\title{
Study on thickness-dependence characteristics of bismuth ferrite (BFO) for ultraviolet (UV) photodetector application
}

\author{
Shahnaz Kossar, R. Amiruddin * (10 and Asif Rasool
}

\begin{abstract}
The present research work reports on the fabrication of ultraviolet (UV) photodetectors using bismuth ferrite $\left(\mathrm{BiFeO}_{3}\right.$, $\mathrm{BFO}$ ) thin films with varying thickness. Using the spray pyrolysis technique, BFO thin films were deposited on the glass substrate at $673 \mathrm{~K}$. The deposited BFO thin films were characterized by Raman and FTIR spectroscopic analysis. The morphological analysis reveals uniform grain distribution for the prepared BFO samples. The optical analysis reveals that transmittance value decreases upon an increase in the thickness of BFO thin films and the calculated optical band gap value lies between 2.0 to $2.3 \mathrm{eV}$. The varying thickness of the BFO active layer was stacked between ITO and Al electrodes and the current-voltage (I-V) characteristics of the fabricated ITO/BFO/Al devices were studied under dark and UV illumination $(\lambda=365 \mathrm{~nm}$ ). It was observed that BFO with an optimum thickness ( $365 \mathrm{~nm}$ ) exhibits higher photoresponsivity of $110 \mathrm{~mA} / \mathrm{W}$ with an external quantum efficiency (EQE) of $37.30 \%$. The impact of different thickness of the BFO active layer, the role of adsorption and desorption of oxygen $\left(\mathrm{O}_{2}\right)$ molecules upon the surface of BFO layers towards UV photoresponse characteristics were investigated.
\end{abstract}

Keywords: Bismuth ferrite, UV photodetector, Oxygen adsorption and desorption

\section{Introduction}

A photodetector is an optoelectronic device that converts the light energy into electrical energy and has potential applications in optical communication [1], spectroscopic instruments [2], defense operations [3], detection of moving objects [4], and also in the biological field [5]. An efficient photodetector can be classified in terms of higher photoresponsivity, large ON/OFF ratio, and low operating voltage [6]. Commercially available silicon ( $\mathrm{Si}$ ) based photodiodes have the potential in the detection of visible light. However, such Si-based photodiodes have demerits such as low sensitivity towards ultra-violet (UV) light and high production costs involved in the fabrication process $[7,8]$. Wide bandgap semiconductors such as $\mathrm{ZnO}$ [9], $\mathrm{NiO}$ [10], and $\mathrm{TiO}_{2}$ [11] based photodetectors were extensively studied towards UV light

\footnotetext{
*Correspondence: amir@crescent.education; amirphy9@yahoo.com Department of Physics, B.S. Abdur Rahman Crescent Institute of Science and Technology, Chennai 600048, India
}

detection applications. Recent research includes study on ferroelectric materials such as $\mathrm{BaTiO}_{3}$ [12], $\mathrm{BiFeO}_{3}$ [13], $\mathrm{Bi}_{0.8} \mathrm{Pr}_{0.2} \mathrm{FeO}_{3}$ [14] and $\mathrm{Bi}(\mathrm{Fe}, \mathrm{Mn}) \mathrm{O}_{3}$ [15] towards fabrication of UV photodetectors [16]. In such ferroelectric materials, the presence of an internal electric field prevents the recombination process between electron-hole (e-h) pairs and facilitates the separation of charge carriers [17]. Among various ferroelectric materials, bismuth ferrite $\left(\mathrm{BiFeO}_{3}, \mathrm{BFO}\right)$ has attracted intensive interest in the fabrication of photonic devices [18]. BFO has a perovskite rhombohedral structure, energy bandgap $\left(\mathrm{E}_{\mathrm{g}}\right)$ of 2.1 to $2.8 \mathrm{eV}$, a large absorption coefficient and higher remanent polarization [18]. The realization of high-quality BFO thin films towards device applications has been successfully reported by various physical methods such as r.f. sputtering [19], pulsed vapour deposition (PLD) [20], molecular vapour epitaxy (MBE) [21]. However, the deposition of BFO thin films using non-vacuum chemical route is of particular interest due to its unique advantages such as low-cost and large-area device processing [22]. 
In the present research work, the BFO thin films with varying thickness were deposited using spray pyrolysis technique on a pre-cleaned ITO coated glass substrate. The effect of BFO thin film thickness on structural, morphological and optical properties was analyzed. The current-voltage (I-V) characteristics under dark and UV illumination were investigated. The role of adsorption and desorption of oxygen molecules towards the photoresponse switching behavior of the fabricated BFObased UV photodetector were investigated.

\section{Experiment}

\section{Materials used}

Bismuth nitrate pentahydrate $\left(\mathrm{Bi}\left(\mathrm{NO}_{3}\right)_{3} .5 \mathrm{H}_{2} \mathrm{O}\right.$, Merck, 99\%), iron (III) nitrate nonahydrate $\left(\mathrm{Fe}\left(\mathrm{NO}_{3}\right) 3.9 \mathrm{H}_{2} \mathrm{O}\right.$, Merck, 99\%), and citric acid $\left(\mathrm{C}_{6} \mathrm{H}_{8} \mathrm{O}_{7}\right.$, purity $\left.\geq 99.5 \%\right)$ were used as precursors source. Nitric acid $\left(\mathrm{HNO}_{3}\right)$ and deionized water were used as a solvent.

\section{Deposition of bismuth ferrite (BFO) thin films}

For the preparation of bismuth ferrite (BFO) thin films, $0.33 \mathrm{M}$ equimolar concentration of bismuth nitrate pentahydrate $\left(\mathrm{Bi}\left(\mathrm{NO}_{3}\right)_{3} . \quad 5 \mathrm{H}_{2} \mathrm{O}\right)$ and ferric nitrate nonahydrate $\left(\mathrm{Fe}\left(\mathrm{NO}_{3}\right)_{3} \cdot 9 \mathrm{H}_{2} \mathrm{O}\right)$ was dissolved in $30 \mathrm{ml}$ deionized water independently and allowed to continuously stir at room temperature for $1 \mathrm{~h}$. Secondly, $10 \mathrm{ml}$ of dilute nitric acid $\left(\mathrm{HNO}_{3}\right)$ was added dropwise to the prepared $\left(\mathrm{Bi}\left(\mathrm{NO}_{3}\right)_{3} .5 \mathrm{H}_{2} \mathrm{O}\right)$ base solution and stirred for $15 \mathrm{~min}$. Finally, $0.33 \mathrm{M}$ of citric acid as a chelating agent was added to the solution and stirred for $30 \mathrm{~min}$. The prepared homogeneous solutions were used to deposit BFO thin films by spray pyrolysis method. The glass substrates were cleaned using detergent and deionized water. Further, ultrasonic cleaning was carried out for 30 min using a mixture of isopropyl alcohol (IPA) and $\mathrm{HNO}_{3}$ solution. The cleaned glass substrate was preheated at $423 \mathrm{~K}$ before the deposition of BFO thin film. The substrate temperature was maintained at $673 \mathrm{~K}$ with the fixed air pressure of 2 mbar. The solution flow rate was $5 \mathrm{ml} \mathrm{min}{ }^{-1}$ and the nozzle-substrate distance was fixed at $15 \mathrm{~cm}$. The prepared BFO thin films were post-annealed at $623 \mathrm{~K}$ for $1 \mathrm{~h}$ under ambient atmosphere. To investigate the impact of the different thickness of BFO thin films in the device performance, the volume of the precursor solution while spraying was varied as 10,15 , and $20 \mathrm{ml}$ and the samples were coded as $\mathrm{BFO}(10), \mathrm{BFO}(15)$ and $\mathrm{BFO}(20)$ respectively. The thickness of the deposited BFO thin films was measured using the Stylus profilometer (DEKTAK XT Stylus Profiler- Bruker, USA) and the value was measured as $243 \pm 7,365 \pm 15$ and $660 \pm 12 \mathrm{~nm}$ for $\mathrm{BFO}(10)$, $\mathrm{BFO}(15)$ and $\mathrm{BFO}(20)$ respectively. The structural study of BFO thin film samples was investigated by Raman spectra using BRUKER RFS 27: Standalone FT-Raman Spectrometer. The surface morphology BFO thin film samples were performed by High-Resolution Field Emission Electron Microscope system (FEI Quanta FEG 200-High). The Fourier transform infrared spectra (FTIR) spectra of the thin film samples were performed using IR Tracer-100-Shimadzu and optical properties were analyzed using UV Visible Spectrophotometer (Thermo scientific Evolution 201).

\section{Device fabrication}

For the fabrication of BFO-based UV photodetector devices, the following steps were processed: indium tin oxide (ITO) was deposited on the ultrasonically cleaned glass substrate $(2.5 \mathrm{~cm} \times 2.5 \mathrm{~cm})$ using the r.f magnetron sputtering method. Commercially purchased ITO target (99.9\% purity, 2 inch, Able targets, China) was used during the sputtering technique. Highly transparent and electrical conducting ITO thin films $(90 ' \Omega / \mathrm{cm})$ were used as a back electrode for the proposed device. BFO with different thickness (243, 365 and 660) were deposited upon the ITO layer using the spray pyrolysis method at $673 \mathrm{~K}$. Aluminum $(\mathrm{Al})$ was deposited as a top electrode using an electron beam evaporation (EBE) approach. Figure 1 shows the schematic diagram of the fabricated device structure (ITO/BFO/Al). The current-voltage (I-V) characteristics of the proposed ITO/BFO/Al device under dark and UV illumination were measured using the Agilent B2901A source measuring unit (SMU) using a scan rate of $0.06 \mathrm{~V} / \mathrm{ms}$. The source of UV light is the commercially purchased monochromatic UV lamp (Wavelength $\chi=365 \mathrm{~nm}$ and power $=4 \mathrm{~mW} / \mathrm{cm}^{2}$ ). The photograph of the fabricated ITO/BFO/Al photodetector and experimental set up used to study the photosensing characteristics is included as supplementary information (see Additional file).

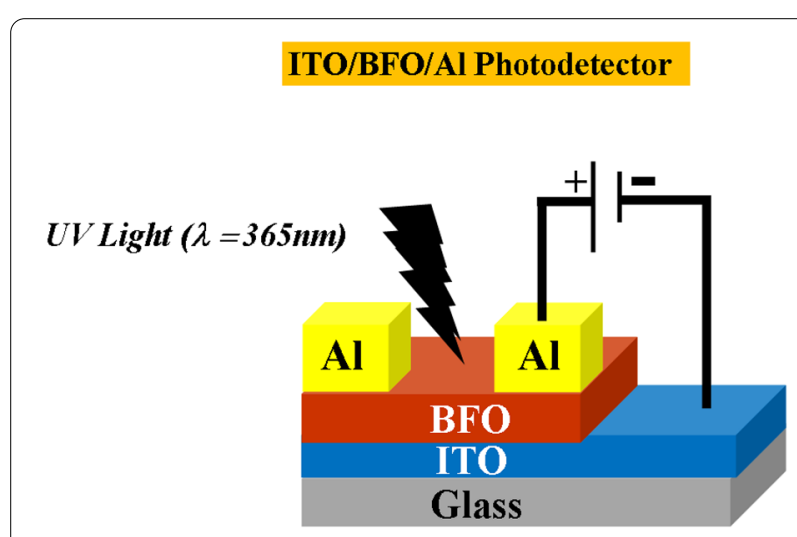

Fig. 1 Schematic diagram of ITO/BFO/Al photodetector 


\section{Results and discussion}

Raman spectroscopic analysis

Figure 2 shows the Raman spectroscopic analysis for (a) BFO (10) and (b) BFO (15). The space group of the $\mathrm{BFO}$ material is $\mathrm{R} 3 \mathrm{c}$ and group theory predicts that BFO should have 13 Raman-active phonon modes summarized as $\hat{\Gamma}=4 \mathrm{~A} 1+9 \mathrm{E}$; where $\mathrm{A}_{1}$ and $\mathrm{E}$ represent the symmetry in rhombohedral distorted structure [23]. In the present study, four optical transverse $\mathrm{A}_{1}$ symmetry [A1(TO)] and six optical transverse E-symmetry [E(TO)] phonon modes were recorded. The Raman modes positioned at 122, 171, 221 and $432 \mathrm{~cm}^{-1}$ can be assigned as $A_{1}-1, A_{1}-2, A_{1}-3$ and $A_{1}-4$ modes respectively. The other six modes positioned at 77.6, 113, 278, 348, 485 and $560 \mathrm{~cm}^{-1}$ can be assigned as E-1, E-2, E-4, E-5, E-7 and E-8 respectively. The low-frequency modes correspond to bismuth $(\mathrm{Bi})$ and oxygen $\left(\mathrm{O}_{2}\right)$ vibrations and the higher frequency modes correspond to $\mathrm{Fe}-\mathrm{O}$ vibrations [24]. The Raman active modes observed in the 160 to $365 \mathrm{~cm}^{-1}$ range were related to the atomic motion of $\mathrm{Fe}$ and $\mathrm{O}_{2}$ molecules in the $\mathrm{FeO}_{6}$ octahedron of BFO [25]. Raman active modes that are identified above $500 \mathrm{~cm}^{-1}$ are ascribed to the stretching vibrations of oxygen atoms [26-28].

\section{FTIR analysis}

Figure 3 shows the FTIR spectra for the BFO (10) and BFO (15). The observed bands located at $646 \mathrm{~cm}^{-1}$ and $828 \mathrm{~cm}^{-1}$ are due to the overlap of $\mathrm{Bi}-\mathrm{O}$ and $\mathrm{Fe}-\mathrm{O}$ groups [29]. These bands are due to the bending vibration of the

$\mathrm{Fe}-\mathrm{O}$ bond within the octahedral unit of $\mathrm{FeO}_{6}$ and $\mathrm{BiO}_{6}$

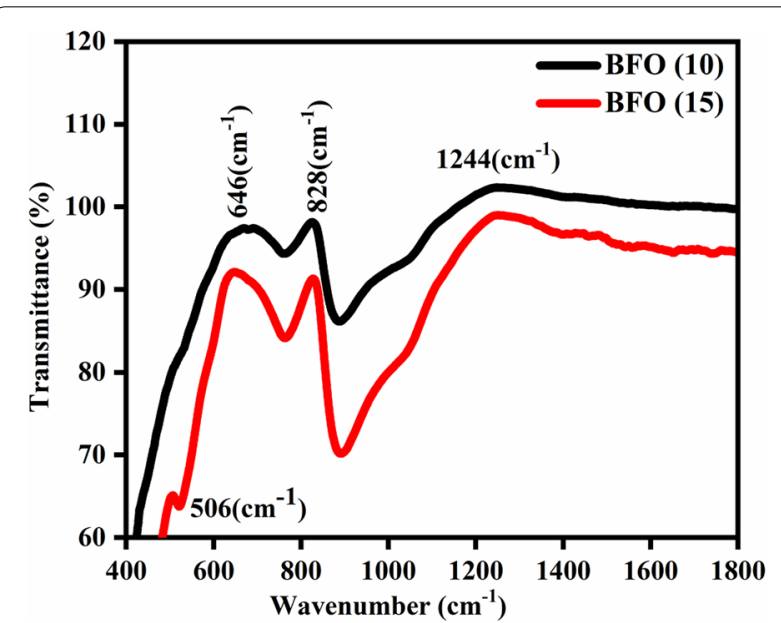

Fig. 3 Fourier transform infrared spectroscopy of BFO (10) and BFO (15) thin films

groups [30]. The characteristic peaks located at $506 \mathrm{~cm}^{-1}$ were related to $\mathrm{O}-\mathrm{Fe}-\mathrm{O}$ bond stretching and $\mathrm{Fe}-\mathrm{O}$ bending of the $\mathrm{FeO}_{6}$ group [31].

\section{Morphological analysis}

Figure 4a-c shows the field emission electron microscopy (FESEM) morphological analysis of BFO (10), BFO (15), and BFO (20) thin films. It was observed by an increase in the thickness of BFO thin films the morphology appears to be more uniform and less porous. For BFO (20) thin films with a higher thickness $(\sim 660 \mathrm{~nm})$, the probability for dislocation density and stacking fault increases, and
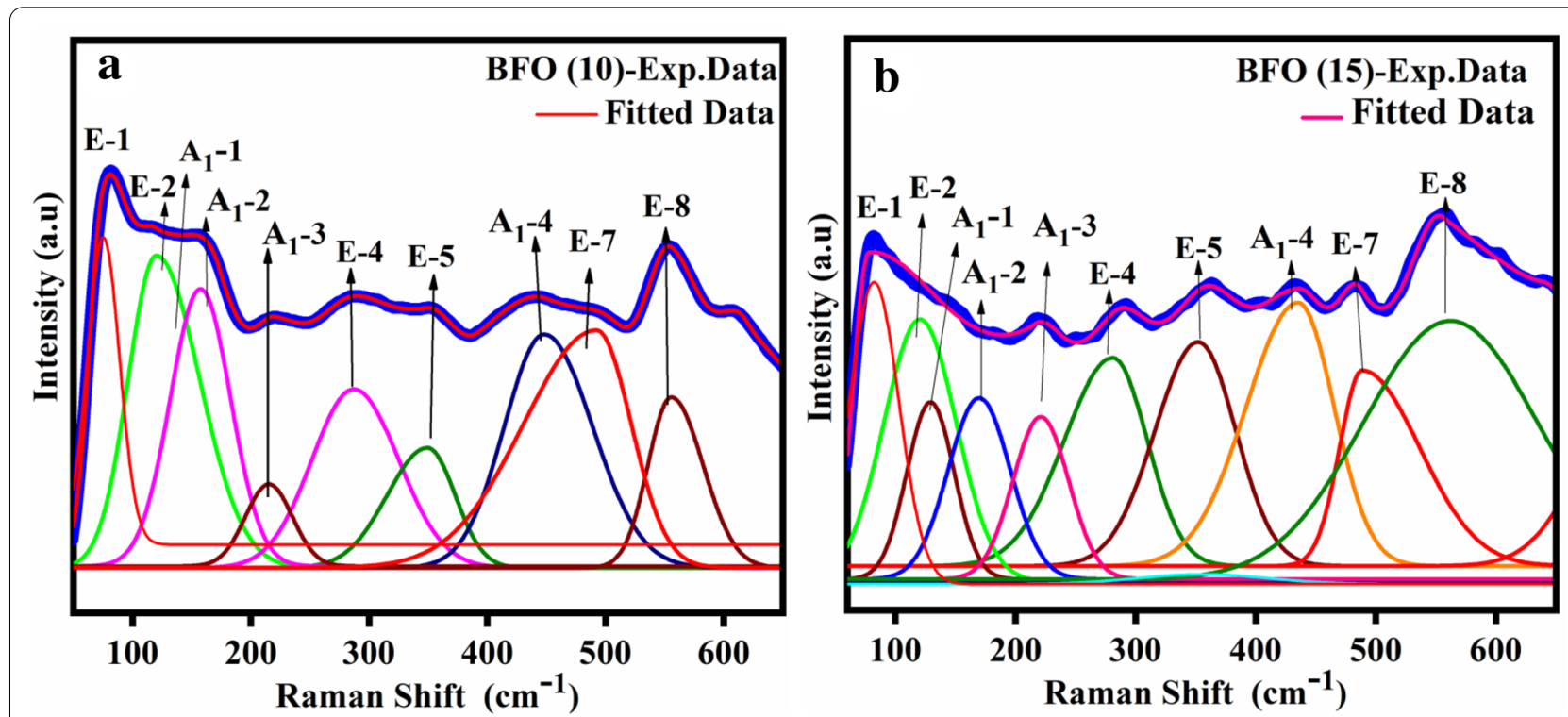

Fig. 2 Raman spectroscopy analysis of BFO (10) and BFO (15) thin films 

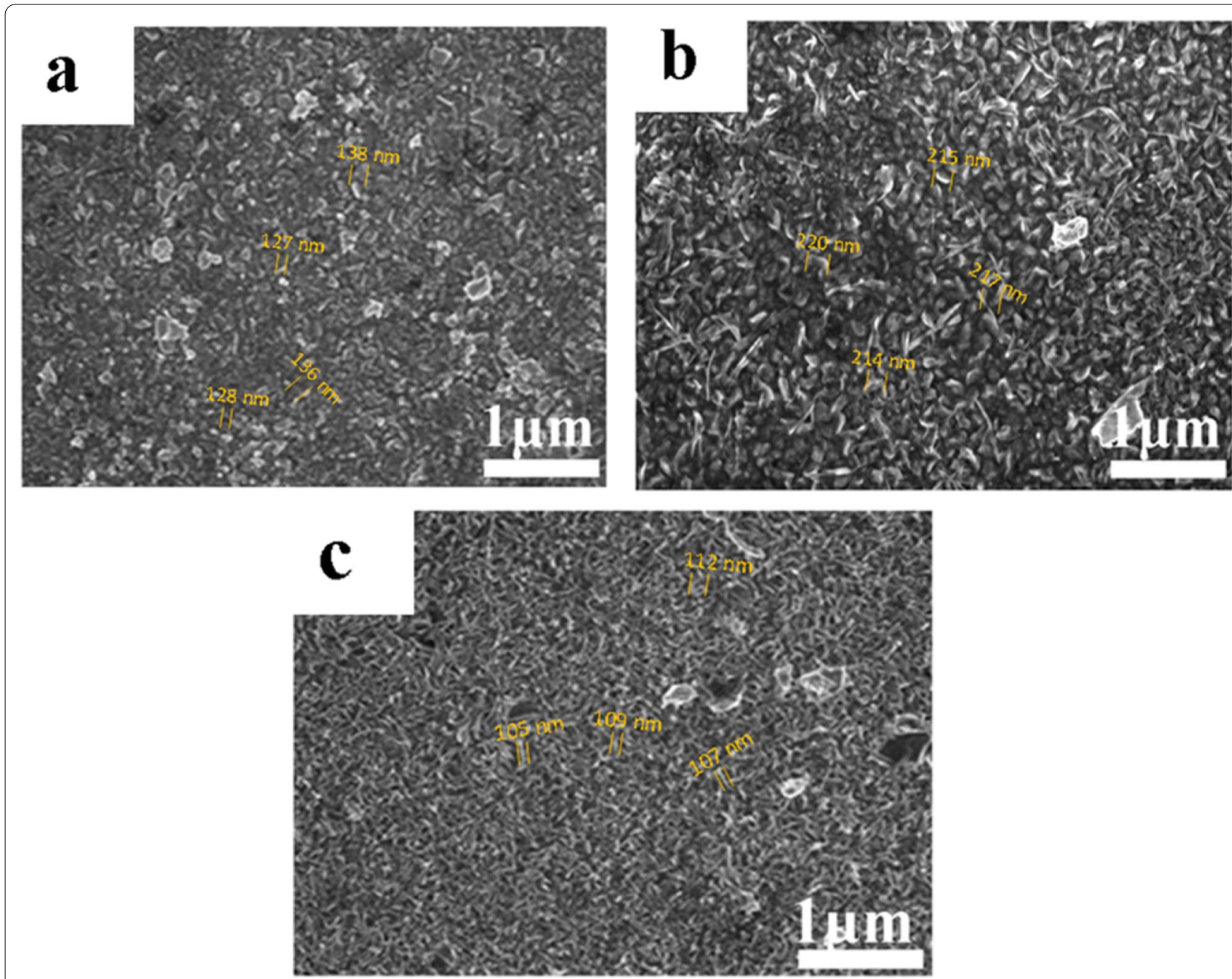

Fig. 4 FESEM micrographs of a BFO (10), b BFO (15) and $\mathbf{c} B F O$ (20) thin films

hence the stress in BFO (20) thin films increases [32]. As a result, the grain size of BFO (20) gets reduces significantly as observed in Fig. 4c.

\section{Optical properties}

Figure 5a exhibits the optical transmittance spectra of BFO (10), BFO (15), and BFO (20) thin films in the wavelength spectrum of $350-1800 \mathrm{~nm}$. An average transmittance between 25 and $60 \%$ in the visible region was observed for all the prepared BFO thin films. The bandgap energy of BFO thin films was determined by extrapolating the linear part of the tauc's graph as shown in Fig. 5b. The calculated optical band gap energy values were found to be $2.3 \mathrm{eV}$ for BFO (10), $2.2 \mathrm{eV}$ for BFO (15), and $2.1 \mathrm{eV}$ for BFO (20). The observed decrease in the value of the bandgap upon an increase in the thickness of the BFO thin films may be due to the increase in grain size of the samples and also due to an increase in the crystallinity of the films $[33,34]$.

\section{Current-voltage (I-V) and photoresponse switching characteristics}

Figure 6 exhibits the current-voltage $(\mathrm{I}-\mathrm{V})$ characteristics of the fabricated (a) ITO/BFO(10)/Al, (b) ITO/ $\mathrm{BFO}(15) / \mathrm{Al}$ and (c) ITO/BFO(20)/Al based photodetector under dark and UV exposure. The obtained I-V characteristic of the fabricated UV photodetector shows linear Ohmic behavior [18]. Notable important parameters to determine the performance of UV photodetector includes photoresponsivity $(\mathrm{R})$ and external quantum efficiency (EQE) and were calculated using the following Eqs. (1) and (2) respectively [35]

$$
\text { Photoresponsivity }(\mathrm{R})=\frac{\mathrm{I}_{\mathrm{UV}}-\mathrm{I}_{\text {Dark }}}{\mathrm{P}_{\text {inc }}}
$$

where $I_{U V}$ and $I_{\text {dark }}$ signify the value of current measured under UV exposure and dark conditions and $P_{\text {inc }}$ 

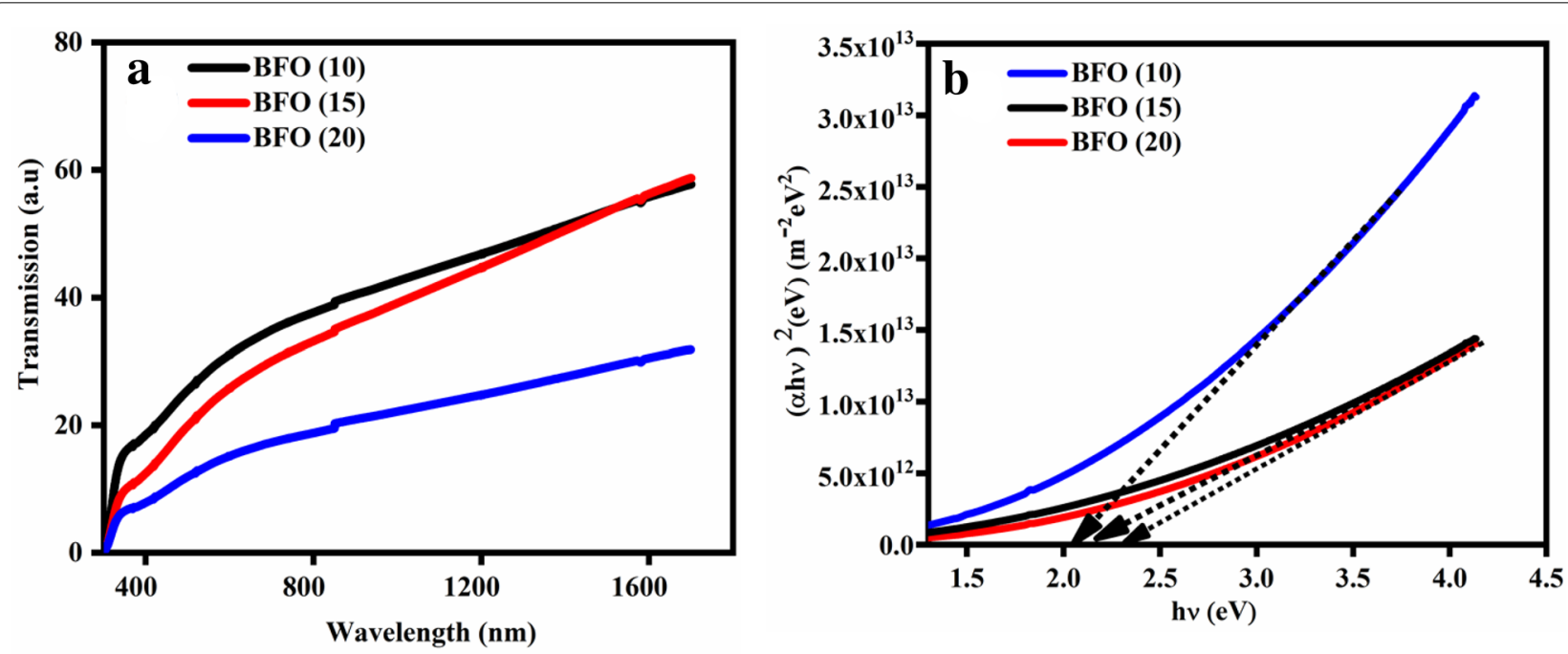

Fig. 5 a Transmission spectra of BFO thin films for BFO (10), BFO (15) and BFO (20) and b Tauc plot of BFO (10), BFO (15) and BFO (20) thin films

represents the power of the incident UV light source $\left(4 \mathrm{~mW} / \mathrm{cm}^{2}\right)$.

$$
\text { External quantum efficiency }(\mathrm{EQE})=\frac{\mathrm{R}}{\mathrm{I}_{\text {incident }}} \times \mathrm{hc} \times 100 \%
$$

Table 1 reveals the UV photoresponse properties of $\mathrm{ITO} / \mathrm{BFO}(10) / \mathrm{Al}, \mathrm{ITO} / \mathrm{BFO}(15) / \mathrm{Al}$ and $\mathrm{ITO} / \mathrm{BFO}(20) / \mathrm{Al}$ based photodetectors. Variation in the obtained photoresponse properties among the fabricated devices shows that the thickness of the active layer plays one of the vital parameters towards the realization of an efficient photonic device [36]. Among the fabricated devices, ITO/ $\mathrm{BFO}(15) / \mathrm{Al}$ photodetector with an optimum thickness of BFO (365 nm) showed higher photoresponsivity (R) of $110 \mathrm{~mA} / \mathrm{W}$ with an external quantum efficiency (EQE) of $37.30 \%$. The reason for the obtained low photoresponse characteristics at higher BFO thickness $(\sim 20 \mathrm{ml})$ of the active layer is due to the limitation in the penetration depth of incident UV photons [37]. It is reported that UV photons interact predominantly with the surface of the active layers for an optimal penetration depth $(\sim 300 \mathrm{~nm})$ and such a thin surface of the active layers contributes towards photoconductivity mechanism [38]. In addition, the photodetector with a thick active layer results in the formation of a small depletion region which tends to capture fewer incident photons. Thus, ITO/BFO(20)/Al photodetector with thick active layer shows low photoresponse characteristics. On the other hand, the obtained less photoresponse property for ITO/BFO(10)/Al photodetector may be attributed due to the formation of a low internal electric field in the $\mathrm{BFO}(10)$ active layer [39]. Figure 7 shows the time-dependent photoresponse switching characteristics of (a) ITO/BFO(10)/Al, (b) ITO/BFO(15)/
$\mathrm{Al}$ and (c) ITO/BFO(20)/Al based devices at a bias voltage of $3 \mathrm{~V}$ under dark and UV illumination $(\lambda=365 \mathrm{~nm}$ and $4 \mathrm{~mW} / \mathrm{cm}^{2}$ ). When the BFO-based photodetector was exposed to UV light, the photocurrent rises dramatically and the photocurrent steadily decreases to its original level when the light is turned off. When the light is irradiated on the BFO based photodetector, electronhole $(\mathrm{e}-\mathrm{h})$ pairs are generated and these photogenerated charge carriers move towards the opposite electrode to contribute to the external photocurrent. The rise time and recovery time for $\mathrm{ITO} / \mathrm{BFO}(15) / \mathrm{Al}$ photodetector were calculated as 6 and $17 \mathrm{~s}$ respectively. Figure 8 shows the working mechanism of ITO/BFO/Al photodetector based on oxygen adsorption and desorption process under dark and UV illumination. During the dark condition, an oxygen molecule is adsorbed by capturing the free electron from the BFO thin film surface and forms a depletion layer near to the surface of BFO. The formation of the depletion region significantly reduces the electrical conductivity of BFO layers. The electron-hole pairs $(\mathrm{e}-\mathrm{h})$ are produced when the ITO/BFO/Al photodetector is illuminated with UV light with the condition $E_{h v}>E_{B F O}$. Such photogenerated charging carriers are driven into the field path by the external bias and neutralize the adsorbed oxygen. The width of the depletion layer will now decrease and the electrical conductivity of BFO thin surface increases under the UV illumination condition [23, 29, 40-42]. However, it can be observed that the obtained photoresponse characteristics of ITO/BFO/Al photodetector do not show a steady-state condition. Such an exponential increase/decrease of photocurrent value with an unsaturated response is termed as persistent photoconductivity (PPC) effect [43]. Such effect occurs 

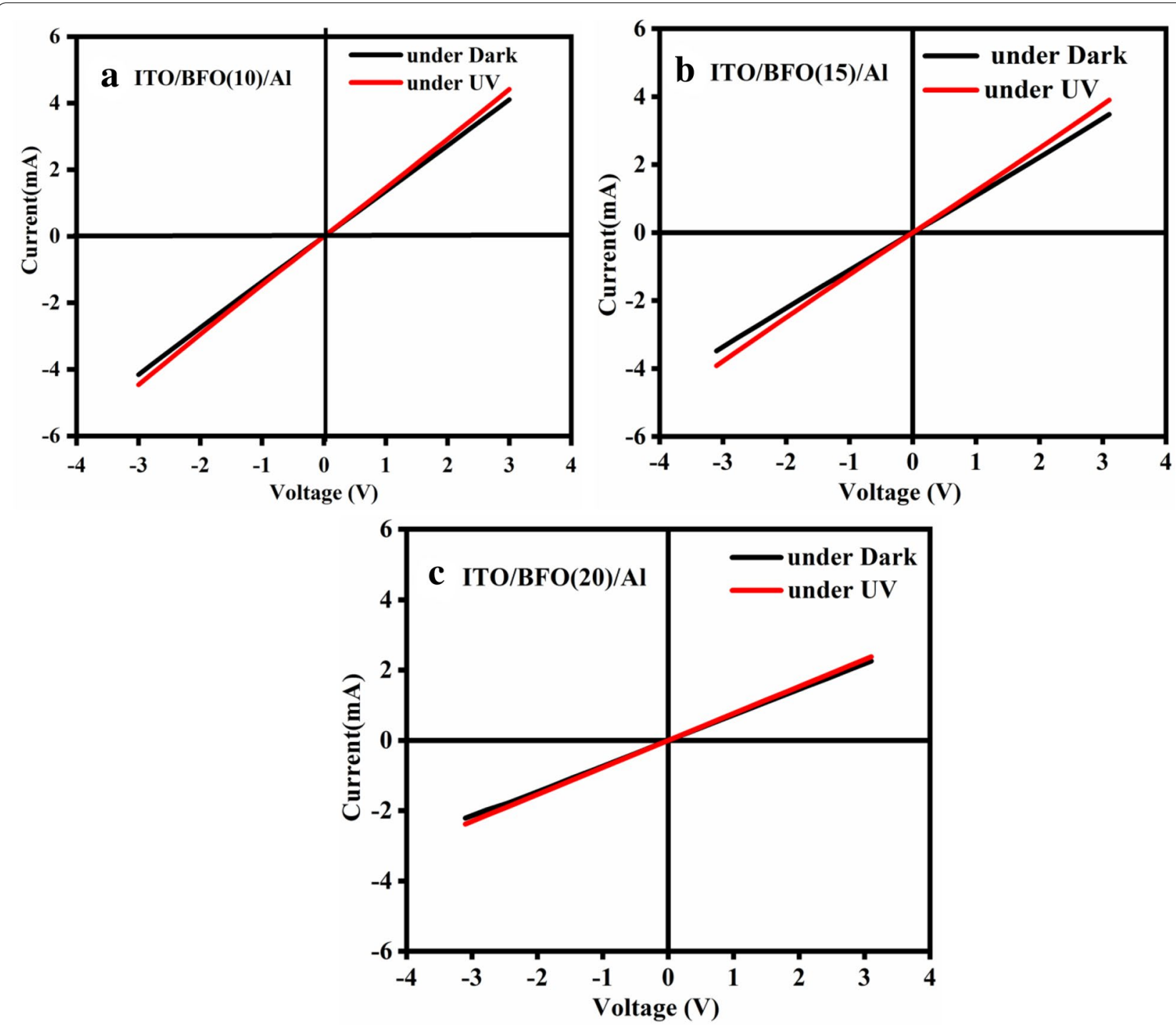

Fig. 6 Current-voltage (I-V) characteristics of the a ITO/BFO (10)/Al, b ITO/BFO (15)/Al and c ITO/BFO (20)/Al

Table 1 UV photoresponse properties of the fabricated BFO (10), BFO(15) and BFO (20) photodetector

\begin{tabular}{llllllrr}
\hline Sample & Thickness & $\begin{array}{l}\text { Photo } \\
\text { responsivity } \\
(\mathbf{m A} / \mathbf{W})\end{array}$ & $\begin{array}{l}\text { Dark current } \\
(\mathbf{m A})\end{array}$ & $\begin{array}{l}\text { Photo current } \\
(\mathbf{m A})\end{array}$ & $\begin{array}{l}\text { External quantum } \\
\text { efficiency (EQE) \% }\end{array}$ & Rise time (s) & Fall time (s) \\
\hline BFO (10) & $243 \pm 7 \mathrm{~nm}$ & 80 & 4.14 & 4.46 & 27.10 & $9 \pm 0.15$ & $22 \pm 0.14$ \\
BFO (15) & $365 \pm 15 \mathrm{~nm}$ & 110 & 3.48 & 3.91 & 37.30 & $6 \pm 0.41$ & $17 \pm 0.39$ \\
BFO (20) & $660 \pm 12 \mathrm{~nm}$ & 42 & 2.21 & 2.38 & 14.20 & $11 \pm 0.17$ & $27 \pm 0.14$ \\
\hline
\end{tabular}

when the re-adsorption of $\mathrm{O}_{2}$ molecules takes place in addition to the desorption process under UV exposure of the fabricated photodetector. Hence, during UV illumination conditions, the generation of electron holes pairs and a simultaneous oxygen re-adsorption process results in unsaturated photoresponse characteristics [46, 47]. Similarly, during a dark condition, the slower re-adsorption rate results in prolonged unsaturated recovery time $[43,44]$. The present analysis correlates the role of oxygen adsorption and desorption process under UV light and 

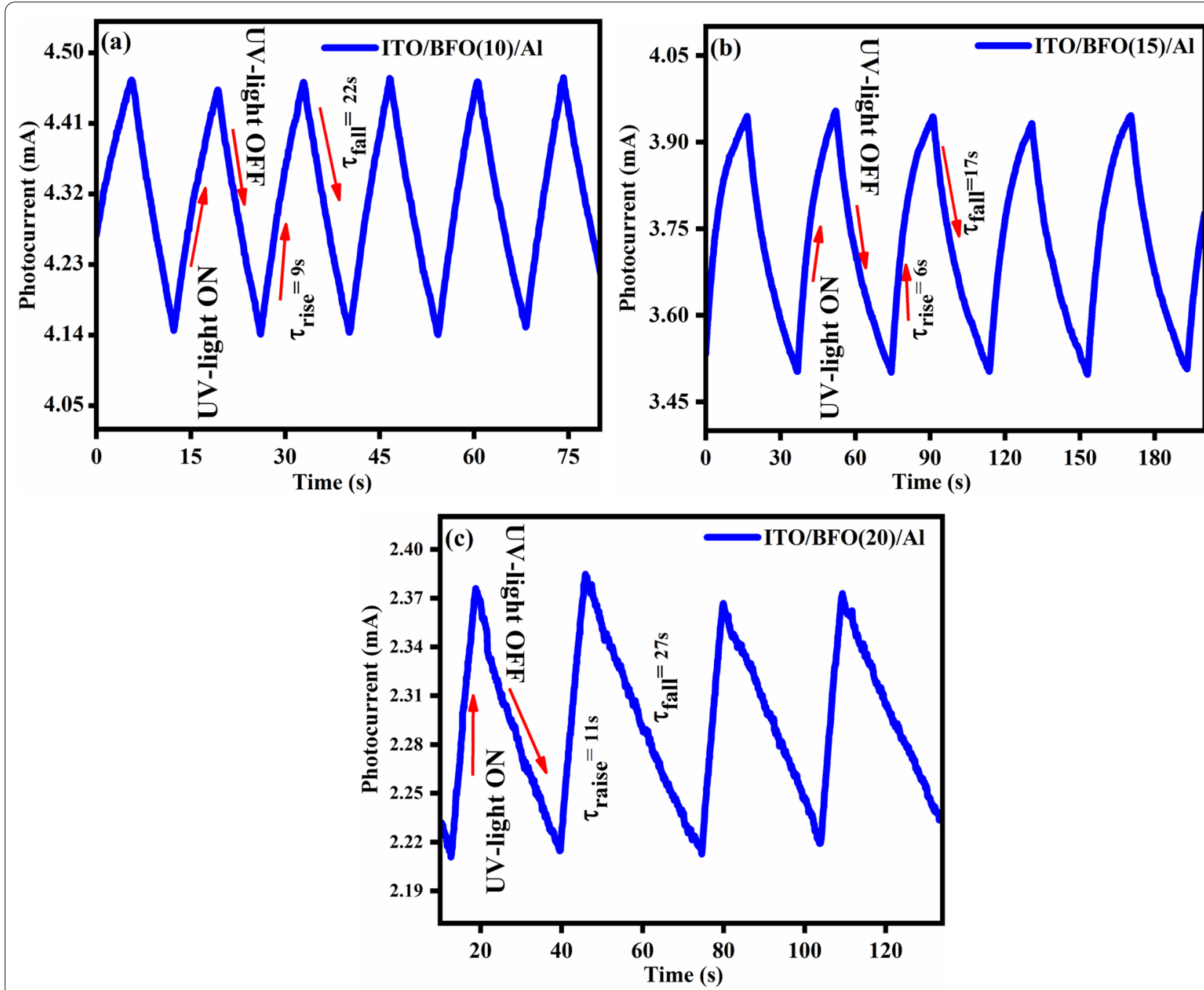

Fig. 7 Time-dependent photoresponse switching characteristics of the a ITO/BFO (10)/Al, b ITO/BFO (15)/Al and c ITO/BFO (20)/Al

a Under Dark Condition Wider Depletion layer

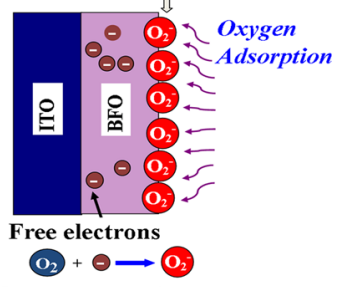

Fig. 8 The working mechanism of ITO/BFO/Al photodetector based on oxygen adsorption and desorption process under dark and UV illumination

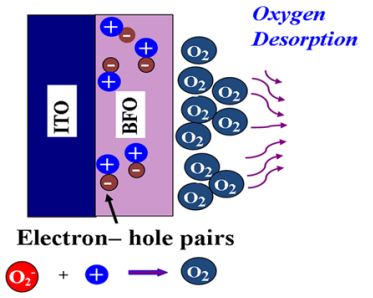

Electron-hole pairs

O/BFO/Al photodetector based

(

b Under UV exposure dark towards the understanding the photoconductivity mechanism of ITO/BFO/Al photodetectors. Table 2 displays the UV photoresponse properties of the fabricated ITO/BFO/Al photodetector compared to earlier studies on BFO-based UV photodetectors.

\section{Conclusion}

The analysis correlates the role of the thickness of the BFO active layer towards the realization of an efficient UV photodetector. The various thickness of BFO thin films was deposited using spray pyrolysis technique and characterized by Raman spectroscopy, FTIR analysis. The morphological and optical analyses were investigated. The BFO active layer was stacked between $\mathrm{Al}$ and ITO electrodes and the current-voltage (I-V) characteristics of the fabricated ITO/BFO/Al were analyzed under dark and UV illumination $(\lambda=365 \mathrm{~nm})$. The $\mathrm{I}-\mathrm{V}$ analysis showed that 
Table 2 UV photoresponse properties of the fabricated ITO/BFO/AI photodetector in comparison with the earlier reports on BFO-based photodetectors

\begin{tabular}{|c|c|c|c|c|c|c|c|}
\hline Device Structure & $\begin{array}{l}\text { Deposition } \\
\text { technique } \\
\text { of BFO active } \\
\text { layer }\end{array}$ & Device configuration & $\begin{array}{l}\text { Photo } \\
\text { responsivity } \\
\text { (A/W) }\end{array}$ & Rise time & Fall time & Working mechanism & Refs \\
\hline ITO/ZnO/BFO/PEDOT:PSS & Spin coating & $\begin{array}{l}\text { Metal/semiconductor/ } \\
\text { ferroelectric/metal }\end{array}$ & 0.04 & $9 \mathrm{~s}$ & $6 s$ & $\begin{array}{l}\text { Formation of the deple- } \\
\text { tion region at the ferro- } \\
\text { electric/semiconductor } \\
\text { junction and the role of } \\
\mathrm{n}+/ \mathrm{n} \text { BFO junction in } \\
\text { the detection of white } \\
\text { light was investigated }\end{array}$ & [13] \\
\hline ITO/BFO/Ag & $\begin{array}{l}\text { Hydrothermal } \\
\text { and post- } \\
\text { sintering } \\
\text { process }\end{array}$ & Metal/ferroelectric/metal & $0.6 \times 10^{-3}$ & $10 s$ & $0.6 \mathrm{~s}$ & $\begin{array}{l}\text { Thermo-phototronic } \\
\text { effect induced electron } \\
\text { transfer in the BFO film } \\
\text { for the detection of UV } \\
\text { radiation }(\lambda=365 \mathrm{~nm})\end{array}$ & [45] \\
\hline $\begin{array}{l}\mathrm{Ag} / \mathrm{CH}_{3} \mathrm{NH}_{3} \mathrm{Pbl}_{3} / \mathrm{BiFeO}_{3} / \\
\text { ITO }\end{array}$ & Spin coating & $\begin{array}{l}\text { Metal/organic semicon- } \\
\text { ductor/ferroelectric/ } \\
\text { metal }\end{array}$ & 2 & $0.74 \mathrm{~s}$ & $0.08 \mathrm{~s}$ & $\begin{array}{l}\text { Formation of } \\
\mathrm{CH}_{3} \mathrm{NH}_{3} \mathrm{Pbl}_{3} / \mathrm{BiFeO}_{3} \\
\text { heterojunction for } \\
\text { infrared photodetector } \\
(\lambda=800 \mathrm{~nm})\end{array}$ & [46] \\
\hline $\mathrm{BFO} / \mathrm{LaAlO}_{3} /(\mathrm{La}, \mathrm{Sr}) \mathrm{MnO}_{3}$ & PLD & Ferroelectric/metal & $1.8 \times 10^{3}$ & $6.97 \mathrm{~ms}$ & $1.27 \mathrm{~ms}$ & $\begin{array}{l}\text { Role of charged domain } \\
\text { walls (CDWs) confined } \\
\text { in (BFO) nanoislands for } \\
\text { detection of visible- } \\
\text { infrared spectrum }\end{array}$ & [6] \\
\hline Pt/BFO & PLD & Metal/ Ferroelectric & - & $25 s$ & $19 s$ & $\begin{array}{l}\text { Role of in-plane platinum } \\
\text { (Pt) electrode configu- } \\
\text { ration for light detec- } \\
\text { tion using Halogen } \\
\text { source }\end{array}$ & [47] \\
\hline ITO/BFO/Al & Spray pyrolysis & Metal/ferroelectric/metal & 110 & $6 s$ & $17 \mathrm{~s}$ & $\begin{array}{l}\text { Oxygen adsorption/des- } \\
\text { orption process upon } \\
\text { the surface of BFO and } \\
\text { thickness dependence } \\
\text { characteristics of the } \\
\text { BFO layer towards UV } \\
\text { photodetection were } \\
\text { analyzed }\end{array}$ & Present work \\
\hline
\end{tabular}

BFO with an optimum thickness (365 nm) exhibits higher photoresponsivity of $110 \mathrm{~mA} / \mathrm{W}$ with an external quantum efficiency (EQE) of 37.30\%. The BFO (15) based device exhibits fast photoresponse characteristics with the rise time of $6 \mathrm{~s}$ and decay time of $17 \mathrm{~s}$.

\section{Supplementary Information}

The online version contains supplementary material available at https://doi. org/10.1186/s40486-020-00128-7.

Additional file 1. The photograph of the fabricated ITO/BFO/Al photodetector and experimental set up used to study the photosensing characteristics is included as supplementary information.

\section{Acknowledgements}

R. Amiruddin wish to acknowledge the award of Crescent seed money (Lr.No. 1239/ Dean (R)/2019) and Shahnaz Kossar wish to acknowledge the Institute fellowship provided by B.S. Abdur Rahman Crescent Institute of Science and Technology (BSACIST), Chennai-600048, Tamil Nadu, India. The author wish to acknowledge the Institute fellowship provided by B.S. Abdur Rahman Crescent Institute of Science and Technology (BSACIST), Chennai-600048, Tamil Nadu, India

Authors' contributions

All authors contributed equally.

Funding

Not applicable. No funding received.

Availability of data and material

Due to the ethical issue of our Institute, authors do not want to submit the raw data. However during the review process, if the editor/reviewer needs to verify the raw data it can be shared. 


\section{Competing interests}

The author(s) declare(s) that they have no competing interests".

Received: 29 February 2020 Accepted: 10 December 2020 Published online: 04 January 2021

\section{References}

1. Chen H, Liu K, Hu L, Al-Ghamdi AA, Fang X (2015) New concept ultraviolet photodetectors Appl Mater 18(9):493-502

2. Yang D, Ma D (2019) Development of organic semiconductor photodetectors: from mechanism to applications. Adv Opt Mater 7(1):1800522

3. Tan CL, Mohseni H (2018) Emerging technologies for high-performance infrared detectors. Nanophotonics 7(1):169-197

4. Wang J, Fang H, Wang X, Chen X, Lu W, Hu W (2017) Recent progress on localized field enhanced two-dimensional material photodetectors from ultraviolet-visible to infrared. Small 13(35):1700894

5. Wang H, Kim DH (2017) Perovskite-based photodetectors: materials and devices. Chem Soc Rev 46(17):5204-5236

6. Wang J, Ma J, Yang Y, Chen M, Zhang J, Ma J, Nan CW (2019) Ferroelectric photodetector with high current on-off ratio $(\sim 1 \times 104 \%)$ in self-assembled topological nanoislands. ACS Appl Mater Interfaces 1(6):862-868

7. Da Silva SC, Ricardo Y, Kuroda R, Sugawa S (2019) A highly robust silicon ultraviolet selective radiation sensor using differential spectral response method. Sensors 19(12):2755

8. Sang L, Liao M, Sumiya MA (2013) Comprehensive review of semiconductor ultraviolet photodetectors: from thin film to one-dimensional nanostructures. Sensors 13(8):10482-10518

9. Monroy E, Omnès F, Calle F (2003) Wide-bandgap semiconductor ultraviolet photodetectors. Semicond Sci Technol 18(4):R33-R51

10. Ahmed AA, Devarajan M, Afzal N (2017) Fabrication and characterization of high performance MSM UV photodetector based on NiO film. Sensor Actuat A Phys 262:78-86

11. Xie Y, Wei L, Li Q, Chen Y, Yan S, Jiao J, Liu G, Mei L (2014) High-performance self-powered UV photodetectors based on $\mathrm{TiO}_{2}$ nano-branched arrays. Nanotechnology 25(7):075202

12. Sharma S, Tomar M, Puri NK, Gupta V (2014) Ultraviolet radiation detection by barium titanate thin films grown by sol-gel hydrothermal method. Sensor Actuat A Phys 230:175-181

13. Mondal S, Dutta K, Dutta S, Jana D, Kelly AG, De S (2018) Efficient flexible white-light photodetectors based on $\mathrm{BiFeO}_{3}$ nanoparticles. ACS Appl Nano Mater 1(2):625-631

14. Kumar S, Kumar P, Walia R, Verma V (2019) Improved ferroelectric, magnetic and photovoltaic properties of $\operatorname{Pr}$ doped multiferroic bismuth ferrites for photovoltaic application. Res Phys 14:102403

15. Xu HM, Wang H, Shi J, Lin Y, Nan C (2016) Photoelectrochemical performance observed in $\mathrm{Mn}$-doped $\mathrm{BiFeO}_{3}$ hetero structured thin films. Nanomaterials 6(11):215

16. Liu JS, Shan CX, Li BH, Zhang ZZ, Yang CL, Shen DZ, Fan XW (2010) High responsivity ultraviolet photodetector realized via a carrier-trapping process. Appl Phys Lett 97(25):251102

17. Teuscher J, Brauer JC, Stepanov A, Solano A, Boziki A, Chergui M, Wolf JP, Rothlisberger U, Banerji N, Moser JE (2017) Charge separation and carrier dynamics in donor-acceptor heterojunction photovoltaic systems. Struct Dyn 4(6):061503

18. Xing J, Guo EJ, Dong J, Hao H, Zheng Z, Zhao C (2015) High-sensitive switchable photodetector based on $\mathrm{BiFeO}_{3}$ film with in-plane polarization. Appl Phys Lett 106(3):033504

19. Siadou N, Panagiotopoulos I, Kourkoumelis N, Bakas T, Brintakis K, Lappas A (2013) Electric and magnetic properties of sputter deposited $\mathrm{BiFeO}_{3}$ films. Adv Mater Sci Eng 4:1-6

20. Zhang GJ, Cheng JR, Rui CH, YU SW, Meng ZY, (2006) Preparation of $\mathrm{BiFeO}_{3}$ thin films by pulsed laser deposition method. T Nonferr Metal Soc 16:s123-s125

21. Laughlin RP, Currie DA, Contreras-Guererro R, Dedigama A, Priyantha W, Droopad R, Theodoropoulou N, Gao P, Pan X (2013) Magnetic and structural properties of $\mathrm{BiFeO}_{3}$ thin films grown epitaxially on $\mathrm{SrTiO}_{3} / \mathrm{Si}$ substrates. J Appl Phys 113(17):17D919
22. Tomczyk M, Bretos I, Jiménez R, Mahajan A, Ramana EV, Calzada ML, Vilarinho PM (2017) Direct fabrication of $\mathrm{BiFeO}_{3}$ thin films on polyimide substrates for flexible electronics. J Mater Chem 5(47):12529-12537

23. Zhang Y, Wang Y, Qi J, Tian Y, Sun M, Zhang J, Hu T, Wei M, Liu Y, Yang J (2018) Enhanced magnetic properties of $\mathrm{BiFeO}_{3}$ thin films by doping: analysis of structure and morphology. Nanomaterials 8(9):711

24. Huang YC, Liou YD, Liu HJ, Lee HH, Chen YC, Chu YH (2017) Magneticcoupled phase anomaly in mixed-phase $\mathrm{BiFeO}_{3}$ thin films. Appl Phys Lett 5(8):086112

25. Ramirez MO, Krishnamurthi M, Denev S, Kumar A, Yang SY, Chu YH, Saiz E, Seidel J, Pyatakov AP, Bush A, Viehland D (2008) Two-phonon coupling to the antiferromagnetic phase transition in multiferroic $\mathrm{BiFeO}_{3}$. Appl Phys Lett 92(2):022511

26. Talkenberger A, Vrejoiu I, Johann F, Röder C, Irmer G, Rafaja D, Schreiber G, Kortus J, Himcinschi C (2015) Raman spectroscopic investigations of epitaxial $\mathrm{BiFeO}_{3}$ thin films on rare earth scandate substrates. J Raman Spectrosc 46(12):1245-1254

27. Hu Y, Fei L, Zhang Y, Yuan J, Wang Y, Gu H (2011) Synthesis of bismuth ferrite nanoparticles via a wet chemical route at low temperature. J Nanomater. https://doi.org/10.1155/2011/797639

28. William RV, Marikani A, Madhavan D (2016) Dielectric behavior and magnetical response for porous $\mathrm{BFO}$ thin films with various thicknesses over $\mathrm{Pt} / \mathrm{Ti} / \mathrm{SiO}_{2} / \mathrm{Si}$ substrate. Ceram Int 42(6):6807-6816

29. Mao W, Chen W, Wang X, Zhu Y, Ma Y, Xue H, Chu L, Yang J, Li XA, Huang W (2016) Influence of Eu and Sr co-substitution on multiferroic properties of $\mathrm{BiFeO}_{3}$. Ceram Int 42(11):12838-12842

30. Singh A, Khan ZR, Vilarinho PM, Gupta V, Katiyar RS (2014) Influence of thickness on optical and structural properties of $\mathrm{BiFeO}_{3}$ thin films: PLD grown. Mater Res 49:531-536

31. Nandy S, Sudakar C (2019) Influence of chemical solution growth and vacuum annealing on the properties of (100) pseudocubic oriented $\mathrm{BiFeO}_{3}$ thin films. J Appl Phys 126(13):135303

32. Kaur G, Mitra A, Yadav KL (2015) Pulsed laser deposited Al-doped ZnO thin films for optical applications. Pro Nat Sci-Mater 25(1):12-21

33. $X u$ JP, Zhang RJ, Chen $Z H$, Wang $Z Y$, Zhang $F$, Yu $X$, Jiang $A Q$, Zheng $Y X$, Wang SY, Chen LY (2014) (2019) Optical properties of epitaxial $\mathrm{BiFeO}_{3}$ thin film grown on $\mathrm{SrRuO}_{3}$-buffered $\mathrm{SrTiO}_{3}$ substrate. Nanoscale Res Lett $9(1): 188$

34. Singh SB, Singh NB, Sharma HB (2011) Study on the effect of thickness on structural and optical properties of nanocrystalline bismuth ferrite $\left(\mathrm{BiFeO}_{3}\right.$ ) thin films. J Adv Mater Res 410:142-147

35. Pandey BK, Dias S, Nanda KK, Krupanidhi SB (2017) Deep UV-Vis photodetector based on ferroelectric/semiconductor heterojunction. J Appl Phys 122(23):234502

36. Zhang Z, Yates JT Jr (2012) Band bending in semiconductors: chemical and physical consequences at surfaces and interfaces. Chem Rev 112(10):5520-5551

37. Amiruddin R, Kumar MS (2016) Role of p-NiO electron blocking layers in fabrication of (PN): ZnO/Al: ZnO UV photodiodes. Curr Appl Phys 16(9):1052-1061

38. Rao TD, KarthikT, Srinivas A, Asthana S (2012) Study of structural,

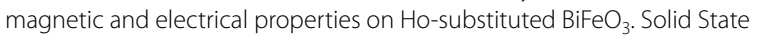
Commun 152(23):2071-2077

39. Iliev MN, Litvinchuk AP, Hadjiev VG, Gospodinov MM, Skumryev V, Ressouche $E$ (2010) Phonon and magnon scattering of antiferromagnetic $\mathrm{Bi}_{2} \mathrm{Fe}_{4} \mathrm{O}_{9}$. Phys Rev B 81(2):024302

40. Yadav HK, Sreenivas K, Gupta V (2010) Study of metal/ZnO based thin film ultraviolet photodetectors: the effect of induced charges on the dynamics of photoconductivity relaxation. J Appl Phys 107(4):044507

41. Rasool A, Santhosh Kumar MC, Mamat MH, Gopalakrishnan C, Amiruddin $\mathrm{R}$ (2020) Analysis on different detection mechanisms involved in $\mathrm{ZnO}$ based photodetector and photodiodes. J Mater Sci Mater 31:7100-7113

42. Srivastav SK, Gajbhiye SN (2012) Low temperature synthesis, structural, optical and magnetic properties of bismuth ferrite nanoparticles. J Am Ceram Soc 95(11):3678-3682

43. Kumar M, Bhatt V, Abhyankar AC, Yun JH, Jeong HJ (2020) Multifunctional dumbbell-shaped $\mathrm{ZnO}$ based temperature-dependent UV photodetection and selective $\mathrm{H}_{2}$ gas detection. Int J Hydrogen Energy 45:15011-21525 
44. Bhatt V, Kumar M, Kim J, Chung HJ, Yun JH (2019) Persistent photoconductivity in Al-doped $\mathrm{ZnO}$ photoconductors under air, nitrogen and oxygen ambiance: Role of oxygen vacancies induced DX centers. Ceram Int 45(7):8561-8570

45. Qi J, Ma N, Ma X, Adelung R, Yang Y (2018) Enhanced photocurrent in $\mathrm{BiFeO}_{3}$ materials by coupling temperature and thermo-phototronic effects for self-powered ultraviolet photodetector system. ACS Appl Mater Interfaces 10(16):13712-13719

46. Upadhyay RK, Singh AP, Upadhyay D, Kumar A, Kumar C, Jit S (2019) $\mathrm{BiFeO}_{3} / \mathrm{CH}_{3} \mathrm{NH}_{3} \mathrm{Pbl}_{3}$ Perovskite Heterojunction Based Near-Infrared Photodetector IEEE. Electron Device Lett 40(12):1961-1964
47. Anshul A, Borkar H, Singh P, Pal P, Kushvaha SS, Kumar A (2014) Photoconductivity and the photo-detection response of multiferroic bismuth iron oxide. Appl Phys Lett 104:132910

\section{Publisher's Note}

Springer Nature remains neutral with regard to jurisdictional claims in published maps and institutional affiliations.

\section{Submit your manuscript to a SpringerOpen ${ }^{\circ}$ journal and benefit from:}

- Convenient online submission

- Rigorous peer review

- Open access: articles freely available online

- High visibility within the field

- Retaining the copyright to your article

Submit your next manuscript at $\boldsymbol{\nabla}$ springeropen.com 